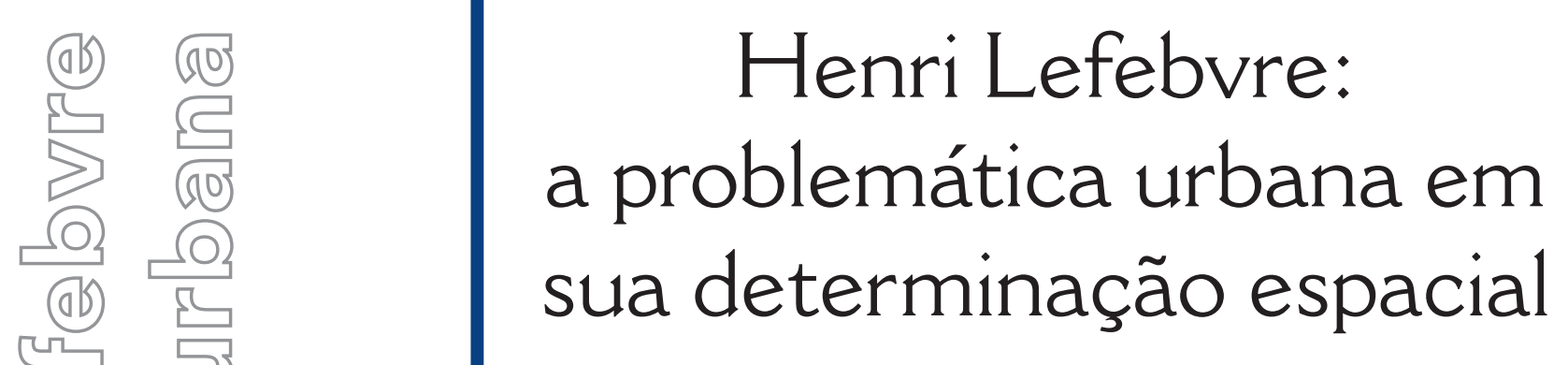

\author{
Ana Fani Alessandri Carlos \\ Universidade de São Paulo
}

\section{revista}

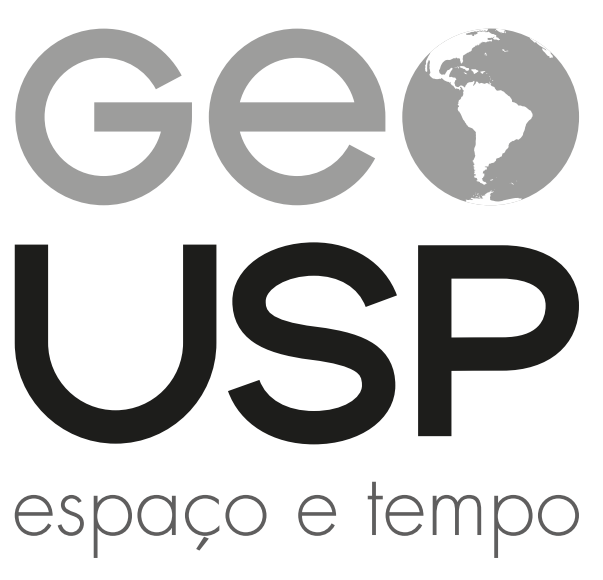

Volume $23 \cdot n^{\circ} 3$ (2019)

ISSN 2179-0892 p. $458-477$

Como citar este artigo:

CARLOS, A. F. A. Henri Lefebvre: a problemática urbana em sua determinação espacial. Geousp - Espaço e Tempo (Online), v. 23, n. 3, p. 458-477, dez. 2019, ISSN 2179-0892.

Disponível em: https://www.revistas.usp.br/geousp/article/view/163371. doi: https://doi.org/10.11606/issn.2179-0892.geousp.2019.163371.

\section{(c) (i) \$}

Este artigo está licenciado sob a Creative Commons Attribution 4.0 Licence 


\title{
Henri Lefebvre: a problemática urbana em sua determinação espacial
}

\section{Resumo}

O objetivo deste artigo é esboçar o momento em que o espaço se configura como elemento constitutivo da problemática urbana na obra de Henri Lefebvre. Ao longo do século XX, a partir de um ponto de inflexão marcado pela ruptura provocada pelo conjunto de mudanças que anunciam a modernidade, encontra-se o evento crucial. $O$ pensamento de Henri Lefebvre sobre a cidade e o urbano é retomado, por um lado, situando o urbano no movimento de passagem da historicidade à espacialidade e, por outro, no "direito à cidade", que projeta o pensamento e a ação para o futuro, prolongando a utopia marxista como o negativo do direito tornado objeto encerrado no âmbito da política pública.

Palavras-chave: Henri Lefebvre. Espaço. Urbano. Direito à cidade. Utopia.

\section{Henri Lefebvre: the urban problematic in its spatial determination}

\begin{abstract}
The aim of this paper is to outline the moment when space is converted in a constitutive element of urban problematic in the work produced by Henri Lefebvre. Throughout the twentieth century, from a turning point marked by the rupture caused by the set of transformations that announce modernity, we can grasp the crucial event. Henri Lefebvre's thought about the city and the urban is resumed, on the one hand, locating the urban in the movement from historicity to spatiality and, on the other hand, the "right to the city", which projects thought and action to the future, extending Marxist utopia as the negative of right made a limited object within the scope of public policy.
\end{abstract}

Keywords: Henri Lefebvre. Space. Urban. Right to the city. Utopia. 


\section{Henri Lefebvre: la problemática urbana en su determinación espacial}

\section{Resumen}

El propósito de este artículo es describir el momento en que el espacio se convierte en un elemento constitutivo de la problemática urbana en el trabajo producido por Henri Lefebvre. A lo largo del siglo XX, desde un punto de inflexión marcado por la ruptura causada por el conjunto de transformaciones que anuncian la modernidad, encontramos el evento crucial. El pensamiento de Henri Lefebvre sobre la ciudad y lo urbano se reanuda, por un lado, ubicando lo urbano en el movimiento de la historicidad a la espacialidad y, por otro, el "derecho a la ciudad", que proyecta el pensamiento y la acción para futuro, extendiendo la utopía marxista como lo negativo de una noción de derecho hecha objeto estricto de la política pública.

Palabras claves: Henri Lefebvre. Espacio. Urbano. Derecho a la ciudad. Utopia.

Produto da dialética entre a continuidade/descontinuidade do processo histórico, a modernidade vem acompanhada do novo, o que requer novos conceitos capazes de iluminar as metamorfoses a partir da prática social. A problemática que permite sistematizar os desafios postos por essa época de modo a esboçar o que existe e determina o presente caracterizando a vida social em seu horizonte de possibilidades revela-se urbana e de ordem espacial. Esta contempla uma realidade em formação e um horizonte de transformação. Para Lefebvre, esse momento tem como referência uma subversão: o que explica o mundo não é mais a história e nem a historicidade, mas a espacialidade. $\bigcirc$ processo assinala uma mudança no sentido da história, no qual não se reconhecem mais os traços da historicidade, no seio do mundial que se anuncia.

Assim, efetiva-se a ruptura no movimento de passagem da historicidade à espacialidade, trazendo consigo uma nova prática associada a uma tendência global (histórica e social) que difere da ordem industrial - como seu negativo -, produzindo novas relações de produção na escala da sociedade inteira. Uma descontinuidade na continuidade do processo histórico se anuncia por um momento crítico caracterizado na prática pela explosão-implosão da cidade, o que significa que a problemática urbana se formula concretamente e se descreve, em sua fase crítica, em vários níveis: da arquitetura, do urbanismo e da vida cotidiana. Esses níveis se articulam, abrindo um novo horizonte: aquele do urbano e da sociedade urbana, num espaço mundializado.

Nesse sentido, a dialética do espaço ganha supremacia sobre a dialética do tempo, inaugurando, para Lefebvre, o período urbano como aquele da trans-história. Isto é, em sua obra, o urbano se formula como momento (crítico) de ruptura no processo histórico da acumulação do 
capital, impactando a vida social. Nessa crise, se "é verdade que o futuro e o possível se esclarecem pelo passado, o futuro reserva surpresas, pois ele se define pelo mundial (espaço) e não pelo histórico (tempo)" (Lefebvre, 1975a, p. 94).

Em Lefebvre, a compreensão do mundo traz consigo o virtual e, nesse sentido, a espacialidade não caracteriza apenas o novo período que se anuncia, mas também o horizonte utópico.

Este projeto de espaço, ${ }^{1}$ obra em escala planetária de uma dupla atividade produtora e criativa (estética e material) [...] comporta uma prova concreta, ligada à prática e à totalidade do possível, segundo o pensamento mais radical de Marx, ligado também à restituição inteira do sensível e do corpo segundo a poesia nietzschiana. Este projeto rejeita na negação os resultados mortos do espaço hegeliano, obra do Estado, onde ele se instala e se estende. Obra e produto da espécie humana, o espaço sai da sombra, como o planeta de um eclipse (Lefebvre, 1975a, p. 223).

Debruçando-se sobre o século XX e esboçando as mudanças na práxis social, a obra do autor é acompanhada da construção de novos conceitos que as explicitem. São eles: a cidade, o urbano, o cotidiano e o espaço (sua produção), que totaliza os demais. Esse é o grande desafio para compreender o século XX na obra de Lefebvre e sua atualidade para pensar o século XXI.

\section{Uma questão de método}

O caminho desenvolvido por Lefebvre para compreender a realidade é aquele construído por Marx e pelo materialismo dialético, cuja obra Lefebvre prolonga pelo movimento do pensamento crítico. Esse movimento se desenvolve a partir da crítica à filosofia clássica pela elaboração do que Lefebvre chama de metafilosofia. Para ele, se a filosofia deixou de lado a prática social, o que chamou de mundo extrafilosófico, portanto, irracional, a obra de Marx, por outro lado, não revela outra coisa senão uma compreensão necessária e profunda da prática social. Nesse caminho, apontou a indissociabilidade entre teoria e prática, trazendo nessa perspectiva a necessidade de confrontar a filosofia com o mundo não filosófico: o mundo da práxis. No plano teórico, se impõe a necessidade de ir além das sistematizações e especulações filosóficas debruçando-se sobre a realidade prática para definir a unidade racional-real, questionando, desse modo, os conteúdos dos conceitos, bem como introduzindo novos, confrontando-os com as ideias de mutação e revolução.

Assim, o conhecimento tem um duplo estatuto: é uma decisão teórica que visa a prática e que a tem como ponto de partida; esta, por sua vez, tem uma existência real e uma da ordem do possível. A realidade sobre a qual se debruça não é fixa nem se encontra acabada, mas em movimento, revelando as determinações que explicitam não só o presente, mas também o devir. Enquanto o social se volta a compreender a práxis, o teórico exige a totalidade. Esta se constitui como:

[...] noção elaborada pelos sistemas filosóficos - mas que Marx insere simultaneamente na elaboração dos conhecimentos parciais e no movimento do real da prática social, compreendendo a ação política. Sem abandonar os resultados das

$1 \bigcirc$ autor refere-se aí ao espaço diferencial. 
análises que fragmentam a realidade (natural, histórica e social) Marx depreende sua racionalidade integrando-as numa exposição global. Ele dissipa as ideologias constituindo uma prática revolucionária. Assim, este pensamento vai e vem da prática à teoria e vice-versa (Lefebvre, 1968b, p. 11-12).

Desse modo, a exigência de que os conceitos se construam pela captura do movimento que vai da teoria à prática demanda que sejam retomados num nível superior. É nesse movimento do pensamento que se dedica a compreender a prática da modernidade que Lefebvre descobre a importância do espaço como determinante do novo processo que se anuncia. Isso ocorre porque, no curso de um vasto processo, o capitalismo se transforma (o que requer novos conceitos). A prática social assinala que o capitalismo em crise precisa do espaço para continuar se reproduzindo, introduzindo-o como elemento da produção da vida bem como da subversão do real. Assim, a produção do espaço ganha centralidade para entender a dinâmica social, o sentido e a direção do processo de reprodução da sociedade por meio da cidade e do urbano.

A cidade - como dimensão espacial - aparece para Lefebvre como um desafio à análise, trazendo problemas novos. A cidade revela que a vida vai aí acontecer e tornar-se visível pela metamorfose das formas urbanas. A industrialização fez a cidade explodir, e essa explosão vai produzir o fenômeno urbano e a subordinação da vida cotidiana a sua lógica. Em seu desenvolvimento, nos encontramos diante do urbano que engloba e transcende a cidade, anunciando sua tendência de se constituir como fenômeno mundial. Assim, o conceito de urbano aparece na obra de Lefebvre, a um só tempo, como realidade concreta e como virtualidade. Esse movimento se depreende da dialética entre teoria e prática; da relação real/virtual, que ilumina as bases sobre as quais se constrói a compreensão do mundo.

Lefebvre se debruça sobre o século XX, quando os fenômenos urbanos aparecem de forma distinta e são novos não só em relação ao pensamento de Marx, mas também em relação ao marxismo, visto que emergiram na época contemporânea e, notadamente, no programa do mercado e da realização da mais-valia, trazendo novas exigências tanto práticas (mudanças nas relações sociais advindas da mudança do processo de acumulação) quanto teóricas (exigência da crítica dos conceitos). Apesar dessa mudança no sentido da história, a análise marxista do século $X X$, como adverte Lefebvre, negligenciou as questões relativas ao espaço e ao urbano, exatamente porque a reflexão marxista se orientou, desde o início, para a análise crítica da produção stricto sensu (isto é, no sentido econômico), uma vez que estava presa à lógica da empresa e do trabalho produtivo, o que significou deixar de lado a amplitude do movimento da reprodução como condição da acumulação - reprodução esta que ao desenvolver a base social tomou também os espaços fora da fábrica estendendo-se à cidade. Só recentemente o pensamento marxista tomou consciência dessa problemática, mas mesmo assim de "modo simplificado" (Lefebvre et al., 1983, p. 54). Um fator importante dessa crítica é que os marxistas não atacaram a ideologia que se produzia, segundo a qual a produção industrial, trazendo em si o essencial da vida social e política, colocaria apenas problemas administrativos. Escreve Lefebvre (1972a, p. 202): 
[...] nessa direção se havia um erro ele dependeria da gestão capitalista da indústria e de uma planificação racional das forças produtivas; tentava-se restituir a coerência do processo de crescimento o que implicaria numa simplificação o real.

Foi assim que os estudos urbanos reduziram, para Lefebvre, a realidade urbana e espacial a problemas com a renda da terra à especulação imobiliária, ao papel dos promotores e dos bancos; o que não é falso, mas trata-se de algo que restringiria a realidade e empobreceria a análise, exigindo a superação dessa situação teórica. Em entrevista, Lefebvre cita como exemplo desse procedimento autores como Castels e Preteceille, especificamente.

Para Lefebvre, compreender a realidade urbana tem na produção do espaço um conceito fundamental que se desdobra do conceito de produção desenvolvido por Marx. Isto é, o estudo da atividade criadora (da produção em sentido amplo) conduz à análise da reprodução, ou seja, das condições em que as atividades produtoras de objetos ou de obras se reproduzem elas mesmas, re-começam, re-tomam seus elos constitutivos ou, ao contrário, transformam-se gradualmente ou por saltos.

A acumulação do capitalismo traz como exigência a renovação incessante do processo de valorização, o que não se faz sem contradições, como a desenvolvida por Marx, baseada na tendência à queda da taxa de lucro que acompanha seu desenvolvimento. As contradições que surgem do processo são constantemente superadas pela invenção de novas possibilidades capazes de ampliar a base social na qual se realiza a acumulação. Desse modo, o desenvolvimento do processo de produção, em seu movimento continuado, ao encontrar seus limites sinalizados como momentos de crise, obriga o questionamento sobre onde e como essas crises se solucionam, permitindo a sobrevivência do capitalismo.

É nesse momento que a instauração do cotidiano e da produção do espaço passam a integrar de forma mais profunda e abrangente o ciclo da reprodução do capital. Isto é, a produção do espaço e a produção da vida humana em todas as suas dimensões passam a subordinar-se à lógica da acumulação. Assim, a resposta à sobrevivência do capital está posta pelo movimento da reprodução que se realiza por meio do cotidiano, do urbano e do espaço.

\section{Sobre o cotidiano}

Na obra de Lefebvre, o cotidiano como categoria de análise - esfera que traz o vivido para o pensamento teórico - permite deslocar o foco e o sentido da produção da esfera do econômico para a do social, sem evidentemente desconsiderar a primeira. $\bigcirc$ cotidiano aparece como exigência da explicação do momento histórico em que, para continuar se reproduzindo, o capitalismo precisa superar sua fase crítica ampliando a multiplicidade de objetos de consumo de todos os tipos, o que faz subsumindo todos os espaços-tempos da vida cotidiana à lógica do capital. A vida invadida pelo tempo produtivo permite instaurar o cotidiano como exigência da acumulação, aprofundando a desigualdade e colocando os indivíduos em relação pela mediação das mercadorias e das imagens.

Para Lefebvre (1961), a cotidianidade comportaria a cisão da vida real em setores definidos e separados em suas funções e organizados como momentos referentes: aquele do trabalho, o da vida privada e o dos lazeres. A separação desses três domínios pode ser observada 
claramente no urbano. A vida cotidiana, nesse contexto, está presa às funções banais e às repetições, ganhando sentido no contexto da reprodução do capital como um espaço de cuidados, que tenderia a constituir-se em um sistema organizado nos mínimos detalhes. Esta situação, como alerta Lefebvre, coloca-nos diante do cotidiano (e não mais da vida cotidiana) como produto do capitalismo e a ele submetido.

$\bigcirc$ estudo do cotidiano determina o lugar em que se formulam os problemas concretos da produção em sentido amplo e do modo como se objetiva a existência social dos seres humanos. Assim, o cotidiano - como realidade e como categoria de análise - aparece como exigência do capitalismo no processo de reprodução da sociedade, num determinado momento da história ligando-se à produção do urbano. Nessa direção, o cotidiano aparece como nível da análise no qual se estabelece o neocapitalismo, já que é o lugar onde se reproduzem as relações sociais para além do lugar do trabalho, ganhando a sociedade inteira, bem como o espaço inteiro.

Movimento importante do método, Lefebvre chama atenção para o fato de que o cotidiano não coincide com a realidade, pois contempla a subjetividade fluída, as emoções, os afetos, os hábitos que dizem respeito ao conjunto da civilização e contemplam a vida do homem. Nesse plano, o homem se depara com as alienações vividas, iluminado as contradições que criam as barreiras que permitem a construção da história humana. Isso significa que o cotidiano implica uma contradição. $\bigcirc$ cotidiano se define pela dialética entre produto da história ao mesmo tempo em que é também um resíduo que escapa ao domínio da mercadoria e de seu mundo e é, por isso, transformador dessa condição. Nesse momento, o uso - como criação e sentido da vida - se confronta com o valor de troca, impondo-se como necessidade de realização do humano, além do capital. Essa é, por exemplo, a situação que move a exigência do direito à cidade, como projeto utópico que aparece na obra de Lefebvre. Isto porque o movimento da reprodução da prática urbana traz o possível como parte do real, que lhe dá sentido e uma orientação aberta ao futuro. Assim, o cotidiano é produto da história, mas é, também, resíduo, o que ilumina o fato de que a realidade não é estritamente homogênea e contém sua própria negação.

\section{Sobre o momento de ruptura na história}

Em Metafilosofia, Lefebvre (1965, p. 142-143) indica que no começo do século XX opera-se uma mutação importante na história: o capitalismo competitivo acabou abalando a velha lógica, de modo que os quadros de referência da vida e da atividade humanas se dissolvem e, como consequência, a história deixa de ser o referencial da vida e de sua compreensão. ${ }^{2}$ Isso significa que podem-se constatar mudanças na cidade e na vida na cidadã desde o plano do sensível e daquilo que se constituiu como habitual e reconhecido ao longos dos séculos até esquemas intelectuais produzidos sobre o cosmos e o mundo. Assim, o período que se inicia tem como ponto de partida a explosão dos referenciais produzidos pela história, compondo as bases fixas que orientavam as formas de pensar e viver. Esse é também o momento em que a velocidade do

2 Ampla mutação: explosão dos referencias, das bases fixas e definidas como a tonalidade, a perspectiva, o espaço newtoniano: "Mudança dos sistemas parciais, ao aspecto finito e definido, mas descontínuo e distinto do que antes, que se integra na cotidianidade, se acrescentam o ilimitado, o indefinido, o infinito talvez de uma consciência de que nenhum horizonte determinado enclausura mais" (Lefebvre, 1965, p. 183). 
tempo na produção industrial sinaliza a constituição de um novo homem, submetido ao tempo linear e à lógica da divisão do trabalho sob o domínio da máquina.

A destruição dos referenciais é central na mudança do sentido da história, evidenciando os novos conteúdos da prática social que se traduzem em profundas transformações nos modos de pensar e viver. Marcas dessa ruptura na história podem se assinaladas na música, em que a tonalidade que referenciava a produção musical dá lugar à atonalidade; na pintura, em que a perspectiva deixa de ser referência para a forma de traduzir o mundo em imagens; na literatura, em que a efemeridade das formas urbanas revela a brutalidade da cidade - a obra de Charles Baudelaire é um momento significativo desse processo.

A modernidade, escreve Lefebvre (1972a, p. 202), "é um fato sociológico e ideológico, o moderno avança precedido ou seguido de suas sombras, crises múltiplas sempre mais frequentes e mais profundas, contradições dramas catástrofes". Nesse momento, que ele define como urbano, o espaço e a cidade aparecem mais claramente como problemas para a investigação. Assim, o que se anuncia com a destruição dos referenciais da história é nossa entrada no período da abstração do tempo e do espaço e da expansão mundial do mundo da mercadoria, com sua lógica, linguagem e formas de representação. $\bigcirc$ novo é a produção global e total do espaço e, segundo Lefebvre (1968b, p. 5), "para entender a nossa época, é preciso de aparelhagem conceitual".

$\bigcirc$ que se pode inicialmente afirmar é que a explosão-implosão da cidade antiga configura o momento crítico e dá sentido à construção da reflexão de Lefebvre, como ponto de construção da problemática urbana, mudando os conteúdos dos problemas sintetizados pelo processo de industrialização - momento da história em que o processo de produção supera, extravasa, o espaço da indústria - e do processo de produção stricto sensu - para tomar a cidade, redefinindo as relações sociais. A industrialização é, aqui, produtora da urbanização. $\bigcirc$ processo de produção pela indução do fenômeno industrial integra a cidade histórica; incorpora à troca os espaços antes desocupados e que se encontram nas franjas da cidade (tornando-os intercambiáveis pelo desenvolvimento do mercado do solo urbano); generaliza a produção e o consumo de mercadorias para toda a sociedade; transforma o espaço social e político em espaço operacional e, nesse sentido, se transforma num dado e instrumento do planejamento sob a intervenção do Estado e, nessa condição, é tornado um elemento fundamental para manter as relações de dominação. Portanto, a produção industrial implicava a urbanização da sociedade, na medida em que o domínio e as potencialidades da indústria exigiam conhecimentos específicos concernentes à urbanização. Assim, após um certo crescimento, a produção industrial produz a urbanização, fornece as condições de seu crescimento.

Desse modo, a industrialização produziu a urbanização e criou as bases que permitiram ao capitalismo reproduzir-se. A realização do ciclo do capital na era da máquina subverteu as relações sociais, produziu um novo homem, que tem seu ritmo de trabalho e seu processo criativo subordinados à divisão de tarefas e à organização da jornada de trabalho imposta pelo contrato de trabatho, no qual o salário definiria o lugar de cada um na esfera social da distribuição da riqueza. Nesse sentido, o ritmo que daí decorre invade a sociedade e determina as relações sociais de modo que o tempo da fábrica comanda a vida e o processo de valorização cria o mundo da mercadoria. Este desenvolvimento como momento necessário do processo de valorização coloca para a análise a 
importância das transformações da vida cotidiana como uma das esferas necessárias à reprodução capitalista, que se desenvolve no bojo da sociedade urbana que se anuncia neste período.

Nesse movimento, todos os espaços-tempos da vida foram subordinados a essa lógica, com transformações nas formas de viver o tempo e produzindo uma nova cidade que começa a expandir-se para além de seus limites e a espalhar-se em subúrbios (explosão da cidade). A implosão-explosão da cidade como momento crítico anuncia a importância do espaço na produção desse novo momento histórico.

A sociedade urbana se anuncia construída nas ruínas da cidade; esse é o ponto crítico que anuncia o momento de ruptura que se explicita com uma subversão: a industrialização, que induziu a urbanização, torna-se induzida. Essa inversão define o novo período que se anuncia.

A construção da problemática urbana é, portanto, produto do movimento da reprodução do processo cíclico do capital que, ao se desenvolver, produz um espaço mais amplo e articulado, ultrapassando o lugar da indústria para tomar aos poucos toda a sociedade e os espaços da vida e fazendo explodir a cidade e com ela os referencias nos quais a vida se sustentava, por meio do desenvolvimento do mundo da mercadoria, ampliando os problemas advindos da produção das coisas, isto é, a produção clássica de mercadorias. $\bigcirc$ que está posto é que o processo de produção capitalista se desenvolve em direção à reprodução, que não se restringe à reprodução do ciclo do capital como processo único de valorização do valor, pois, nesse momento da história, o capital se dirige ao espaço, produzindo-o como momento da produção no qual se produz o novo urbano.

\section{Sobre o momento crítico}

$\bigcirc$ livro $O$ direito à cidade começa com uma afirmação, do meu ponto de vista, de grande importância para pensar o mundo da segunda metade do século XX e um ponto de inflexão do pensamento sobre a realidade que se metamorfoseia e exige explicação: a inversão na prática social da industrialização produtora da urbanização obrigando-o a uma subversão teórica que se formularia pela passagem de uma sociedade industrial para uma sociedade urbana. Aqui se esclarece um duplo movimento: num primeiro momento a industrialização induziu um processo de urbanização e num segundo momento - que só foi possível diante de um salto qualitativo decorrente do crescimento promovido pela industrialização - a urbanização se torna indutora das transformações sociais. A inversão de perspectiva consiste justamente em considerar a industrialização como etapa da urbanização e como um momento intermediário. No duplo processo (industrialização-urbanização), o segundo momento torna-se dominante após um período no qual o primeiro prevalecia (Lefebvre, 1970, p. 128).

A urbanização, que deixa de ser induzida pela indústria, assume a forma indutora das transformações no seio da sociedade que se anuncia como urbana. Assim, o momento da produção industrial, ao se desenvolver, continha e desenvolvia o seu outro anunciando a sociedade urbana. A industrialização, indutora da urbanização, é portanto um ponto de partida da reflexão de Henri Lefebvre por meio do apelo ao método progressivo-regressivo.

Essa transformação situa-se e anuncia uma zona crítica. A industrialização faz a cidade explodir e com isso estender-se desmesuradamente, construindo um tecido urbano que recobre 
as reminiscências da cidade anterior e, com elas, sua urbanidade, seu tempo lento, sua vida cotidiana. A industrialização permitiu, ainda, a generalização da mercadoria, a extensão ampliada da base do capital. Isto é, a reprodução do ciclo do capital não pode se manter sem ultrapassar a esfera específica do ciclo do capital associado ao processo fabril, e esse crescimento se estende ao espaço inteiro, criando novas áreas articuladas ao capitalismo em sua extensão, o que destrói os espaços e tempos naturais, impondo novas contradições (o tempo linear se impõe ao tempo cíclico tanto no plano da produção quanto naquele da vida). Esse raciocínio vem acompanhado do debate sobre a distinção entre crescimento e desenvolvimento, quer dizer, entre crescimento gradual e salto no desenvolvimento das forças produtivas, inaugurando uma fase crítica e um momento negativo (negação esta que não coincide com a supressão, nem liquidação, mas uma superação). A indústria permitiu o desenvolvimento do processo capitalista transformando o mundo pelo desenvolvimento da ciência da técnica e permitiu sua extensão espacial pelo intercâmbio e pelas trocas por meio do crescimento da produção mercantil com o predomínio do valor de troca. Nessa expansão, invadiu e subsumiu a vida cotidiana cooptando as relações sociais, reproduzindo-se a partir de sua lógica e dando vigor ao movimento produção-reprodução no seio da acumulação capitalista por meio da urbanização sob pressão do mercado mundial. No processo:

[...] as forças produtivas permitem a quem a dispõe de dominar o espaço e mesmo de produzi-lo. Essa capacidade produtiva se estende ao espaço terrestre. $\bigcirc$ espaço natural é reduzido e transformado em um produto social pelo conjunto das técnicas, da física à informática; deste modo, o espaço se de um lado reproduz ativamente as relações de produção, de outro, contribui a sua manutenção e consolidação (Lefebvre, 1973a, p. 112).

movimento da expansão do processo de acumulação envolve o momento do reprodutível e do repetitivo e aventa a expansão do mundo da mercadoria, cujo desenvolvimento contempla a complexificação das relações sociais supondo a criação de novas formas sociais e novos valores e ideias, bem como de novas de formas de viver, com a criação de estilos diferenciadas e a produção de outra cidade. Esse movimento de expansão da produção industrial anuncia uma mudança qualitativa em que:

[...] a problemática urbana desloca e modifica profundamente a problemática saída do processo de industrialização. Enquanto a maioria dos teóricos e também dos "práticos" que procedem de maneira empírica considerando a urbanização como uma consequência menor, quase acidental do processo essencial, a industrialização, nós afirmamos o inverso. Passa-se nesse processo de duplo aspecto uma coisa importante: em termos clássicos um salto qualitativo. $\bigcirc$ crescimento quantitativo da produção econômica produziu um fenômeno qualitativo que se traduz por um problema novo: a problemática urbana. É essencial tomar consciência e conhecimento para não perpetuar um erro teórico e prático que consiste em desdobrar da racionalidade da empresa, experiência da industrialização, modelos e esquemas 
aplicáveis à realidade urbana em formação [...]. Ora, a racionalidade da empresa, sua organização, a divisão do trabalho que ela comporta, foi aquisição essencial do período industrial, mas não convém mais ao período que se anuncia que deve elaborar uma nova racionalidade: a racionalidade urbana (Lefebvre, 2000, p. 72).

Nesse movimento, a realidade urbana, a um só tempo ampliada e estilhaçada, perde os traços da época anterior, povoando-se de signos do urbano como uma ordem repressora. A industrialização, potência dominante e coercitiva, converte-se em realidade dominada no curso de uma crise profunda na qual o passado e o possível, ou melhor, o futuro, misturam-se. $\bigcirc$ urbano que se constitui não se reduz ao industrial nem a ele está submetido. A realidade urbana se constitui como o negativo da realidade saída do processo de urbanização induzido pela industrialização e configura um salto à frente para definir os novos conteúdos do urbano. No horizonte da segunda metade de século XX, esse urbano não só é produto do salto qualitativo que nasce no seio da urbanização associada ao processo de industrialização, mas abre a perspectiva para pensar que o futuro da sociedade é o urbano. Em sua dupla determinação, essa nova fase da história é ao mesmo tempo realidade-possibilidade.

Sintetizando, o urbano que se anuncia é o negativo do processo que fez da industrialização um fator indutor da urbanização. Esta, por sua vez, à medida que se constitui como realidade, aponta um movimento em direção ao devir: sociedade urbana como horizonte do possível. Assim, a extensão do processo de industrialização coloca para Lefebvre uma hipótese mais abrangente: a da urbanização total da sociedade. Isso significa dizer que se a industrialização está posta no horizonte da análise urbana como um elemento para o debate no qual a problemática urbana avança e transcende a problemática posta pela industrialização, como seu negativo. É nesse sentido que, para Lefebvre, a problemática urbana se desloca e modifica profundamente a problemática saída do processo de industrialização, constituindo um salto qualitativo importante.

Portanto, no plano teórico, o conceito de urbano tal como formulado por Lefebvre permite descrever um duplo processo: o da implosão-explosão da cidade antiga, o que significa que a sociedade urbana se constitui sobre a ruína da cidade - o momento em que o processo de reprodução se realiza em outro patamar -, e o da produção/reprodução do espaço como necessidades da produção de novos espaços de acumulação, acompanhada da instauração do cotidiano como produto do desenvolvimento da história. Esse movimento se realiza como movimento da reprodução social e se embasa em novos referenciais: o da mercadoria e o de seu mundo, definido pela ampliação do processo de valorização do valor. É assim que a problemática industrial se desloca e se torna urbana: ligando-se ao espaço.

O urbano (sinônimo, para Lefebvre, de sociedade urbana) é real e virtual e revela, em sua universalidade, a orientação e o conteúdo da realização da vida. Neste momento, o que explica o mundo não é mais a história e nem a historicidade, mas a espacialidade. Lefebvre situa esse momento - anunciador do período trans-histórico - no processo de implosão-explosão da cidade antiga como movimento do ciclo industrial de produção - reprodução em sua fase crítica.

Uma nova problemática que se anuncia - a urbana - tem por conteúdo o espaço. Desse modo, o urbano nasce de uma crise. $\bigcirc$ urbano como realidade (aqui nos referimos a seu aspecto prático) e como conceito (plano teórico) designa precisamente essa crise (Lefebvre, 1986). 
Portanto, o termo "sociedade urbana " não pode ser empregado a propósito de qualquer cidade ou vila histórica; na perspectiva definida por Lefebvre ele designa uma realidade em formação, em parte real e em parte virtual, o que quer dizer que a sociedade urbana não está acabada. Ela se faz num movimento em direção do devir. É uma tendência que já se manifesta como realidade ao mesmo tempo em que está destinada a se desenvolver. Esse inacabamento se formula numa hipótese que orienta as reflexões do autor em várias de suas obras. $\bigcirc$ livro A revolução urbana assim se inicia:

Nós partimos de uma hipótese teórica: a urbanização total da sociedade, hipótese que será sustentada por argumentos, corroborada por fatos. Esta hipótese implica uma definição. Nós denominaremos "sociedade urbana" a sociedade que resulta da urbanização completa, hoje virtual, amanhã real. Esta definição coloca um fim à ambigüidade do emprego dos termos (Lefebvre, 1970, p. 7).

A elaboração da problemática urbana anunciada por Lefebvre acentua, nesse sentido, uma questão importante: o urbano contempla o possível e não o real em si, petrificado. Assim, o mundo se faz mundo tornando-se o que era virtualmente (Lefebvre, 1978b, p. 435). Por sua vez, as virtualidades abrem, em cada época, uma pluralidade de possíveis que se cumprem no processo histórico registrando, para o autor, o salto qualitativo do histórico ao mundial. Segundo Lefebvre, essa mundialidade se estabelece com o predomínio do espaço sobre o tempo, que foi totalizado no espaço, pois ele contém o tempo (um emprego de tempo, uma vez que o espaço social só existe no uso). Portanto, a predominância da espacialidade que se anuncia faz parte da mundialidade. ${ }^{3}$ Todavia, a relação historicidade-mundialidade é conflituosa, pois "o conflito entre historicidade-mundialidade resolve-se na produção de um espaço mundial enquanto obra do tempo histórico no qual este se realizou" (Lefebvre, 1978b, p. 94). Como momento histórico, o urbano como novo conceito ilumina a nova realidade e as virtualidades postas no horizonte para a sociedade. Assim, ao mesmo tempo em que o conceito anuncia uma nova realidade, designa uma tendência à concentração e extensão do fenômeno que se abre agora ao plano mundial. Resta saber quais os conteúdos desse momento assinalado da história, por Lefebvre em que a constituição de uma sociedade urbana se coloca como realidade, exigindo a redefinição conceitual que explicita esse novo momento.

A ideia desenvolvida por Lefebvre de que a realidade contempla o real e o virtual é fundamental para iluminar os momentos que resistem à ordem e à racionalidade impostas pela lógica do capital, informando-nos de que existe, na realidade, um momento de negação ao estabelecido, isto é, uma contradição entre real e possível.

\section{Situando o tema da cidade nas transformações do processo histórico}

Para Lefebvre, não é suficiente formular questões teoricamente, pois os problemas e questões situam-se na prática. Teoria e prática compõem uma dialética que contempla a pesquisa das possibilidades que orientam o estudo do real e dos fatos. Assim, a problemática urbana

3 "[... a história perdeu a dignidade eminente e a perda de referencial (declínio já percebido por Nietzsche). Desde então ela perdeu apresenta, instante e obsessão da lembrança e não, mais que representação" (Lefebvre, 1978b, p. 94). 
se constitui como uma necessidade prática e explicita as mudanças operadas no seio da história da sociedade.

O urbano surge na obra de Lefebvre como questão teórica e prática na década de 1960 , anunciando uma nova prática social (urbana) e política (planejamento), a partir de mudanças nas formas das cidades e na vida que se delineia com essas transformações.

Em Introdução à modernidade, Lefebvre (1969a) reflete sobre a transformação de sua cidade promovida pelo projeto das Cidades Novas na França e sinaliza a ruptura do processo da história acima delineado. Ele escreve:

Mourenx ensinou-me uma coisa. Aqui os objetos têm o título de sua existência social: sua função. Cada objeto serve e o diz. Sua função é bem distinta e bem própria. Tudo nela será funcional e cada objeto melhor caso quando a cidade nova for acabada e bem sucedida, tudo nela será funcional e cada objeto terá sua função própria [...]. O objeto reduzido a sua função e a sua significação aproxima-se do sinal e o conjunto desses objetos de um sistema de sinais [...]. $\bigcirc$ objeto reduzido à significação se confunde com a coisa nua desprovida de sentido [...]. $\bigcirc$ texto que oferece a cidade aos nossos olhos é perfeitamente legível tão pobre quanto claro apesar dos esforços dos arquitetos para variar as linhas. A surpresa? $\bigcirc$ possível? Desvanecidos nesse lugar que deveria ser o das possibilidades [...]. Em Mourenx, eu não leio os séculos, nem o tempo, nem o passado, nem o possível [...]. Eu percorro a modernidade, eu leio sobretudo os temores que ela pode inspirar: o abstrato, que entra com força no vivido - a síntese ilusória que não chega mais a reconstruir um ato - a estrutura morta, impotente [...] (Lefebvre, 1969a, p. 140-141).

A modernidade vem acompanhada pelo processo de abstração que penetra na vida. Quanto mais funcional é o espaço, menos se presta à apropriação e a seu uso político pela sociedade e se concretiza, portanto, como domínio de uma classe.

A burguesia projeta o a separação projetando nas Cidades Novas onde tudo o que pode ser separado e tudo o que unia a vida social, o que era unido natureza e o homem, o ser e o pensamento, se dissociam. Tudo se separa e, no entanto, tudo se totaliza [...] sobre todo esse campo imenso de fragmentos humanos, o Estado se levanta e vela [...]. A tendência à totalização e integração dissimula as separações [...]. A tendência a totalização e à "integração" (no conjunto social, isto, é, no Estado) dissimula as separações. $\bigcirc$ esmigalhamento da cotidianidade, muito mais vasto que o do trabalho (que desaparece já no horizonte) dissimula a unificação pelo alto e a supressão das diferenças originais. Ora a verdade encontra-se no movimento de conjunto. É ela que propõe aos olhares este texto obscuro e legível: a cidade nova (Lefebvre, 1969a, p. 143). 
"Como prática espacial e de planificação espacial", o projeto das Cidades Novas a que Lefebvre se refere acima era coordenado na França pela Délégation Interministérielle à l'Aménagement du Territoire (Datar). Para ele, o projeto que sai da prancheta define a cidade sem passado, máquinas de habitar como produto da razão analítica (Lefebvre et al., 1983, p. 51). Nesse momento, Lefebvre identifica a passagem da construção do habitar à reprodução da cidade como momento que ele define como aquele do habitat. Enquanto o primeiro dá sentido à vida sinalizando a cidade do reino do uso, o segundo se projeta - pelo urbanismo e pela planificação - como funcionalidade. A cidade histórica começa a ser remodelada sob a hegemonia capitalista, com a expansão das periferias e os esforços de planificação. A cidade nova, que surge deste projeto político, não tem lugar para o sonho e para a fruição do tempo no espaço que são elementos fundantes da vida em sociedade. Planejada, ela projeta na cidade uma nova lógica: a urbana.

Com o desenvolvimento do mundo da mercadoria, o crescimento do mercado mundial, que ganha uma força enorme, vem acompanhado por novas tecnologias, e pela constituição de uma nova classe, que Lefebvre vai definir como aquela dos burocratas. Se antes o capitalismo, em seu desenvolvimento, havia se apoderado da agricultura, a partir de 1960 a emergência do fenômeno urbano que vem da explosão da cidade histórica, de seu rearranjo e da expansão das periferias está associada aos esforços de planificação. Os projetos objetivam mudar a cidade, seu uso e seu acesso.

Foi nestas condições que eu tentei introduzir um conceito, aquele de produção do espaço, o espaço como produto social e político, espaço como produto que se vende e compra [...]. A cidade se estabelece com brutalidade extraordinária, a cidade é decidida de cima para baixo, os guindastes chegam e arrasam a cidade [...]. Há um espaço produzido a partir de 1960 na escala mundial com a aviação, auto-estradas, periferias, explosão das cidades históricas, conurbações que precisava ser compreendido (Lefebvre, 1969a, p. 144).

É preciso conceber as mutações por meio das quais a sociedade industrial se transforma em sociedade urbana. No livro Espace et politique, Lefebvre apresenta a ideia de que é necessário superar a ideia banal de que a sociedade contemporânea está mudando em direção à compreensão daquilo que está na base das mudanças. As transformações que Lefebvre identifica nas cidades, nos anos 1960, partem de uma constatação formal e levam-no a pensar no lugar e no sentido dessas transformações no seio da reprodução da sociedade capitalista. A construção da problemática urbana não exclui a crítica ao urbanismo tornado ideologia.

A reprodução e o reprodutível colocam questões novas:

[...] não é somente a sociedade inteira que se torna o lugar da re-produção (das relações de produção e não somente os meios de produção), mas o espaço inteiro. Ocupado pelo neocapitalismo, setorizado, reduzido a um meio homogêneo e, portanto fragmentado, esmigalhado, (só fragmentos de espaço se vende à clientela) o espaço torna-se a sede de poder (Lefebvre, 1973a, p. 112). 
Neste momento, a cidade se coloca como problema para a análise do mundo. O método dialético orienta a compreensão da história como totalidade, o que supõe a implicação dos termos movimento-totalidade e história-práxis. Dois movimentos do método se impõem: (a) no método progressivo-regressivo descobre-se a história da cidade - ao situar sua produção-reprodução no tempo histórico - e, assim, encontra-se o espaço. Desse modo, na reflexão de Lefebvre, a história da cidade se constrói como a história do espaço. É no movimento de retorno à história que ele se depara com uma ruptura: sob o capitalismo, a cidade deixa de ser obra para ser um produto do modo de produção e, nessa condição, domina a sociedade ao impor uma nova lógica a seu uso, outrora tempo social de desfrute e fruição da vida. Na reflexão de Lefebvre, a cidade se constitui ao longo de um processo histórico que a produz como obra, mas que, sob o capitalismo, se torna um produto, (b) no movimento que ele denomina transdução, o urbano como sinônimo de sociedade urbana (como apontado no livro $A$ revolução urbana) aparece na dialética entre real-virtual, o que significa que o urbano que se anuncia é uma realidade em construção, quer dizer, a sociedade urbana não existe ainda e existe virtualmente.

É um conceito teórico apreendido, liberado através de um processo que se apresenta a nós [...] é uma forma (que traz um nome a simultaneidade) do encontro e da reunião de todos os elementos da vida social desde os frutos da terra até os símbolos e as obras culturais [...] se manifesta no seio de um processo negativo da dispersão, da segregação, como exigência do encontro da reunião da informação. Enquanto forma tem um nome: simultaneidade (Lefebvre, 1968a, p. 160).

O urbano, que se revela como momento da reprodução saído da história da industrialização, ao mesmo tempo aponta a tendência da constituição de uma sociedade urbana como resultado da urbanização, quase que completa, da sociedade. Esse é o movimento do negativo anunciado por uma revolução urbana. Essa revolução urbana é uma mudança radical esboçada na segunda metade do século XX e aparece na obra de Lefebvre em sua dimensão atual e como devir da sociedade, isto é, como a realização do projeto humano apontado por Marx. Essa transformação ou revolução pela qual a sociedade industrial se transforma em sociedade urbana, determinando a problemática do real, é uma tendência que situa a sociedade urbana na transição destes momentos. Segundo Lefebvre (1970, p. 183, tradução nossa), os "fenômenos e implicações da indústria apenas começaram a declinar". Desse modo, o que parecia subordinado - a urbanização à industrialização - eleva-se ao primeiro plano: a urbanização torna-se hegemônica revelando o novo momento da história. Essa hipótese desenvolvida por Lefebvre em muitas de suas obras escritas nos anos 1960-70 (e esboçadas neste artigo) adquirem potência para pensar o século XXI, iluminado a centralidade das categorias: o urbano, o cotidiano e o espaço.

\section{O urbano: uma aproximação do conceito}

A práxis contempla a dupla determinação da atividade humana, é produtora e criadora de obras (incluindo o tempo e o espaço sociais). Em resumo, o conceito de produção envolve a produção material, a fabricação de coisas (a produção do mundo da mercadoria), mas também a 
produção espiritual e humana. $\bigcirc$ conceito de produção também se abre para pensar a produção do ser humano por si mesmo no decorrer de seu desenvolvimento histórico.

A produção, tomada em sua plenitude, envolve a criação e caracteriza o ser humano. Esse ser produz e se produz. Não há somente produção de objetos, mas a produção de relações sociais e a produção do espaço e do tempo, produção de relações, produção e reprodução de si (a consciência [reunião da prática e do conhecimento na consciência em si] e do outro [o mundo]) (Lefebvre, 1981, p. 45).

Ao longo do processo histórico, a cidade vai se produzindo com as características de uma civilização distinta da natureza. Ela sintetiza uma ação de apropriação da natureza como condição e obra da ação humana ao longo do processo histórico que se estende ao espaço como consequência do movimento do processo de reprodução as relações de produção um mundo real e objetivo. A construção do conceito de urbano situa-se nesse debate. Em síntese, três momentos dessa construção esclarecem as transformações do real como momentos do desenvolvimento da modernidade em seu desdobramento, salientando três dimensões que acompanham a transformação da realidade que se eleva ao plano do conhecimento:

Em primeiro lugar, ele se manifesta no seio de um processo negativo distinto daquele da cidade, isto é, se manifesta na explosão da cidade tradicional (histórica) sob o processo de industrialização e vem acompanhado da deterioração da vida urbana. $\bigcirc$ urbano se produz no contexto da produção civilizatória e revela a relação espaço-tempo, que no capitalismo torna-se um tempo restrito àquele do processo produtivo (o linear em oposição ao cíclico). Daí se estruturam os ritmos impostos pela racionalidade urbana, como momento da modernidade que vem acompanhado por uma consciência da efemeridade e da fugacidade impostas pelas separações (da natureza e do homem social, do ser e do pensamento, do processo de trabalho etc.), projetadas nos lugares inaugurando o período da abstração vivida concretamente na cidade. Estabelece-se numa prática espacial opressiva/repressiva. Desse modo, o conceito sublinha aquilo que se passa e tem lugar fora das empresas e do trabalho, se bem que ligado por múltiplos liames à produção. Ele põe a ênfase no cotidiano na vida das cidades (Lefebvre, 1968a, p. 160).

Em seu desdobramento, o urbano como horizonte, revela a universalidade do fenômeno, bem como sua orientação em direção ao mundial, inaugurando uma nova prática global (histórica e social) com sua problemática urbana que difere da ordem industrial e produz novas relações de produção na escala da sociedade inteira. Mas, na obra de Lefebvre, o urbano não se constitui como uma essência, visto que é antes de mais nada uma forma:

[...] aquela do encontro e da reunião de todos os elementos da vida social, desde os frutos da terra (trivialmente, produtos agrícolas) até os símbolos e as obras ditas culturais. $\bigcirc$ urbano se manifesta no seio de um processo negativo da dispersão, da segregação, como exigência do encontro, da reunião da informação (Lefebvre, 2000, p. 77).

Em segundo lugar, o conceito de urbano se elabora em Lefebvre a partir de uma teoria sobre o espaço (social) como produto-produtor, isto é, a produção do espaço é engendrada pelo 
modo de produção, na medida em que cada uma delas produz seu próprio espaço. Isso significa que o espaço tem uma história que não se reduz:

[...] nem à das técnicas, nem à das trocas, nem à das revoltas e revoluções (que tiveram suas causas e suas razões). Essa é também a história do espaço e do tempo, "produtos" que não podemos definir nem como materiais nem como imateriais, mas antes como abstrações concretas que entram na prática. $\bigcirc$ espaço ao mesmo tempo em que a comunicação e a informação, sai da prática no modo de produção e reage sobre ela: espaço das estradas, dos meios de locomoção, mas também das megalópolis, das periferias mal delimitadas, das redes múltiplas que se ligam, dos fluxos de produtos, de capitais, de ganhos, de especulações sobre os terrenos, das atividades diversas, bancos e promotores que dominaram e exploraram o espaço assim produzido (Lefebvre, 1986, p. 160).

momento da reprodução que caracterizaria o período atual, que, para Lefebvre, ilumina a importância do espaço como categoria de análise para compreender o mundo moderno, coloca a necessidade da produção do espaço como condição de sua reprodução continuada. Esse processo se move nos termos da reprodução e não da produção; da espacialidade e não da historicidade.

Em terceiro lugar, o urbano aparece como sinônimo de sociedade urbana, contemplando uma hipótese teórica que concerne ao possível e a sua realização com o atual (o real).

urbano é o possível definido por uma direção, no fim do percurso que vai em direção a ele. Para atingi-lo, para realizá-lo é preciso em princípio romper os obstáculos que atualmente o tornam impossível [...] o conhecimento teórico deve mostrar o terreno e a base sobre os quais ele se funda: uma prática social em marcha, a prática urbana em via de constituição [...] o objeto virtual não é outra coisa que a sociedade planetária, a cidade mundial, [...] o urbano é virtualidade em andamento esta potencialidade que já se realiza constitui um campo cego para aqueles que se prendem na racionalidade já superada o que a nega e a destrói - a segregação generalizada - a separação no terreno de todas a prática social dissociadas uns dos outros e reagrupadas por decisão política no seio do espaço homogêneo (Lefebvre, 1970, p. 27-28).

○ urbano, como horizonte, contém o projeto da realização do homem na sociedade urbana, isto é, a revolução urbana é o horizonte aberto à realização civilizatório como o negativo da sociedade urbana capitalista.

\section{Sobre a atualidade do pensamento de Lefebvre}

Assinalamos quatro pontos que julgamos importantes - apesar de insuficientes e inconclusivos - sobre a potência da instigante obra de Henri Lefebvre para compreender s realidade urbana no século XXI: 
(a) no século XX, se produz na sociedade um conjunto de transformações e mutações que sinalizam a passagem de uma sociedade industrial para uma sociedade urbana. Isso caracteriza nosso tempo por meio de uma lógica completamente diferente da urbanização posta pelo processo industrial, o que faz grande diferença na compreensão do mundo moderno. Como apontado acima, a industrialização, que proporcionava a chave para entender o processo de urbanização, "como motor das transformações sociais" e como elemento caracterizador da sociedade moderna, perdeu poder explicativo. A urbanização elevada a um novo patamar não se reproduz mais subsumida ao processo industrial. $\bigcirc$ campo da reprodução das relações sociais se transforma, expandindo-se.

A inversão da realidade proposta por Lefebvre traz exigências teóricas, implica transformação no plano teórico no momento em que "a problemática urbana prevalecerá, em que a busca das soluções e das modalidades próprias à sociedade urbana passará em primeiro plano" (Lefebvre, 1972a, p. 19). Desse modo, caracterizando nossa época, o urbano seria uma chave para entender as contradições e opressões que permeiam a vida. Quais são as consequências teóricas desse movimento de inversão dos processos reais apontado por Lefebvre?

No percurso, a análise se abre à produção do espaço e à instauração do cotidiano como elementos necessários da reprodução do capital (e da sociedade capitalista). Trata-se de elementos que apontariam a superação da centralidade do processo de trabalho e da contradição capital-trabalho na explicação do processo de acumulação no século XXI. Aqui ganham centralidade os conceitos de urbano, produção do espaço e cotidiano, como momentos da reprodução das relações sociais, bem como lugares onde se colocarão as resistências às forças homogeneizadoras do Estado neocapitalista.

Esta reprodução das relações de produção não coincide mais com a representação dos meios de produção: elas se efetuam através da cotidianidade através dos lazeres e a cultura, através da escola e da universidade, através das extensões e proliferações da cidade antiga, quer dizer através do espaço inteiro (Lefebvre, 2000, p. 40).

(b) $\bigcirc$ movimento de compreender a realidade que sinaliza o caminho que vai de sua produção a sua reprodução, ao sinalizar o papel do espaço nesse processo, foca a importância do imobiliário e lhe confere um sentido importante na acumulação do Capital como momento da reprodução do espaço. Em seu desdobramento, podemos afirmar que o que há de novo nesse processo hoje é que a condição do processo de reprodução se faz pela ampla aliança entre frações do capital (industrial e financeiro) e o Estado. Aqui, o que se pode chamar de "setor imobiliário " revela que, em determinado momento, a reprodução se realiza como "conquista do espaço", isto é, o processo de reprodução do espaço aparece como estratégia de realização do capital financeiro na medida em que este passa a investir na produção imobiliária como aplicação de capital - na compra e venda de suas parcelas (na especulação imobiliária, nas grandes obras promovidas pelo Estado). 
Assim, a capacidade produtiva se estende ao espaço e é um dos momentos anunciadores do novo no processo histórico engendrado no processo de reprodução do urbano pela conquista do espaço:

Esse é o caminho (imprevisto) da socialização das forças produtivas, da própria produção do espaço. $\bigcirc$ imobiliário se refere a especulação e a construção na sociedade neocapitalista. $\bigcirc$ imobiliário, como se diz, desempenha o papel de segundo setor, de um circuito paralelo ao da produção industrial voltada ao mercado dos "bens não duráveis" ou menos duráveis que os imóveis. Esse segundo setor absorve os choques. Em caso de depressão, para ele afluem os capitais (Lefebvre, 1970, p. 212).

Esse campo hoje aberto à pesquisa tem como fundamento a compreensão dos sentidos e das consequências do processo de reprodução do espaço urbano. Nesse caminho, supera-se a ideia de espaço como palco onde se desenvolvem e distribuem as atividades humanas. Trata-se, portanto, de pensar em sua produção. Esse movimento da análise permite desvendar o papel ideológico do urbanismo e do planejamento neste processo, de extrema importância para compreender a reprodução das cidades nos dias de hoje, por meio de projetos de renovação urbana.

(c) $\bigcirc$ debate estabelecido por Lefebvre sobre o campo cego - os conteúdos do processo constitutivo do urbano que a análise esconde - traz um alerta necessário para questionar as políticas públicas como projeto de transformação/superação das crises vividas na cidade. A existência desse campo cego alude à necessidade de uma crítica radical ao existente e ao modo como se constrói a compreensão desse momento da história. Com isso, Lefebvre quer dizer que tanto as ciências parcelares como a ideologia urbanista (redutora da prática do habitar e da realidade urbana) encobrem a vasta operação do capitalismo como opressor do valor de uso. Isto é, o uso produtivo - a cidade produzida dentro dos estritos limites da produção econômica como condição da produção/reprodução do capital - se impõe ao uso improdutivo do espaço, centrado na vida cotidiana, como momento de realização da vida pelo urbanismo - produtor de uma forma de ver a cidade - e do planejamento como ação que orienta as transformações da cidade. A ideologia urbanística, escreve Lefebvre (1981, p. 144-145):

[...] é redutora da prática real, a prática dos cidadãos, que desaparece, destinada ao silêncio e à passividade. $\bigcirc$ urbanismo oculta sob a aparência positiva, humanista e tecnológica a estratégia capitalista, o domínio do espaço, a luta contra a queda tendencial do lucro médio. Essa estratégia oprime o usuário, o participante, o simples habitante. Ele é reduzido não apenas à questão do habitar (isto é, ao habitar como função), mas à função de comprador do espaço e, com isso, realizando a mais-valia. Deste modo o espaço torna-se o lugar de funções dentre as quais a mais importante é velada: formar, realizar, distribuir, de uma maneira nova, o sobre-produto da sociedade inteira (isto é, o modo de produção capitalista, a mais-valia global). 
O caminho aberto é a superação do imediatismo como justificativa à elaboração de políticas públicas e mata as condições do devir.

(d) $\bigcirc$ direito à cidade como necessidade para pensar os embates e possíveis avanços dialetiza as políticas públicas postas como solução dos conflitos que se realizam no urbano. $\bigcirc$ movimento de seu pensamento, que entende o mundo como real e virtual, aponta na direção de que a utopia faz parte do conhecimento e faz parte da construção do que chama de projeto possível-impossível. Lefebvre constrói ao longo de várias de suas obras a ideia de que nossa sociedade está permeada de resistências de todos os tipos que ainda não encontraram a reunião capaz de potencializá-las num projeto radical de transformação, o que não significa que não está aí sinalizado que a sociedade urbana é um projeto em construção. Esse horizonte ainda não foi alcançado, e é preciso continuar a busca, encontrando as fontes da resistência e sua capacidade de reunião.

Nesse raciocínio se situa o debate sobre o "direito à cidade", conceito que hoje faz parte do campo cego (onde estão muitos dos estudos urbanos brasileiros) que é preciso superar.

$\bigcirc$ direito à cidade pode aparecer como mediação entre o hoje e o projeto de transformação radical, na medida em que o direito à cidade como:

[...] direito à vida urbana, à centralidade renovada, aos locais de encontro e de trocas, aos ritmos da vida e empregos de tempo que permitam o uso pleno e inteiro desses momentos e locais, etc. [...] pode construir o caminho que conduz ao direito à cidade aponta para a proclamação e a realização da vida urbana como reino do uso (Lefebvre, 1968a, p. 139).

Assim, o autor dialetiza a centralidade dada às políticas públicas e traz como exigência o pensamento teórico - hoje subestimando pelo imediatismo - e, com isso, "visa à realização de outra humanidade que não a sociedade produtiva e diferente da sociedade produtivista [...]. As técnicas, a arte e o conhecimento passam a serviço da cotidianidade a fim de metamorfoseá-la" (Lefebvre, 1968a, p. 143). Esse é o caminho traçado por Lefebvre, capaz de definir a realização da filosofia. Assim, seu pensamento sobre a cidade e o urbano, o cotidiano e a produção do espaço são categorias de análise que concorrem decisivamente para compreender o novo que se anuncia com a modernidade.

\section{Referências}

LEFEBVRE, H. Espace et politique. Paris: Anthropos, 2000.

LEFEBVRE, H. Vida cotidiana no mundo moderno. São Paulo: Ática, 1991.

LEFEBVRE, $H$. Le retour de la dialectique: 12 mots clés pour le monde moderne. Paris: Messidor/Sociales, 1986.

LEFEBVRE, H. O fim da história. Lisboa: Don Quixote, 1981.

LEFEBVRE, H. Une pensée devenue monde. Paris: Fayard, 1980.

LEFEBVRE, H. De 1'Etat. Paris: Union Générale, 1978a. v. 3. 
LEFEBVRE, H. De 1'Etat. Paris: Union Générale, 1978b. v. 4.

LEFEBVRE, H. Hegel, Marx et Nietzsche: ou le royaume des ombres. Paris: Castermam, $1975 \mathrm{a}$.

LEFEBVRE, H. Les temps de méprises. Paris: Stock, 1975b.

LEFEBVRE, H. La survie du capitalisme. Paris: Anthropos, 1973a.

LEFEBVRE, H. De lo rural a lo urbano. Barcelona: Península, 1973b.

LEFEBVRE, H. Espace et politique. Paris: Anthropos, 1972a.

LEFEBVRE, H. La pensée marxiste et la ville. Paris: Casterman/Poche, $1972 \mathrm{~b}$.

LEFEBVRE, H. La révolution urbaine. Paris: Galllimard, 1970.

LEFEBVRE, H. Introdução à modernidade. Rio de Janeiro: Paz e Terra, 1969a.

LEFEBVRE, H. Posição contra os tecnocratas. São Paulo: Documentos, 1969b.

LEFEBVRE, $H$. Le droit a la ville. Paris: Anthropos, 1968a.

LEFEBVRE, H. L'irruption: de Nanterre au sommet. Paris: Anthropos. 1968b.

LEFEBVRE, H. Métaphilosophie. Paris: Syllepse, 1965.

LEFEBVRE, H. Critique de la vie quotidienne. Paris: L'Arce, 1961. v. 2: Fondements

d'une Sociologie de la Quotidienneté.

LEFEBVRE, H.; BURGEL, Galia; BURGEL, Guy; DENEUX, J.-F. Henri Lefebvre répond à V. E. P. Villes en Parallèle, n. 7, déc. 1983. Marxisme et géographie urbaine. p. 51-63. 